\title{
Managing plant genetic resources using low and ultra-low temperature storage: a case study of tomato
}

\author{
Dariusz Kulus ${ }^{1}$ (10)
}

Received: 26 October 2018 / Revised: 25 January 2019 / Accepted: 2 February 2019 /

Published online: 11 February 2019

(C) The Author(s) 2019

\begin{abstract}
Ex situ preservation of plant genetic resources is essential. Tomato is one of the most important vegetable crops on the market. However, the genetic diversity of the clade is limited and suffering from genetic erosion phenomenon. Genebanks experience alleles loss on regeneration of small samples, genetic drift, and somaclonal variation in in vitro cultures. Therefore, the development of more efficient ex situ preservation protocols is required. Storage of accessions at low temperatures allows for the reduction of cell metabolic activity and medium or even long-term preservation. Working and active collections of tomato seeds can be stored at $+5{ }^{\circ} \mathrm{C}$, at reduced humidity. Medium-term storage of seeds and pollen can be performed at freezing temperatures $\left(-20{ }^{\circ} \mathrm{C}\right.$ or $\left.-80{ }^{\circ} \mathrm{C}\right)$. This, however, is highly limited as it requires special freezers and can affect the fecundity of the specimens. As for long-term storage, cryopreservation in liquid nitrogen $\left(-196{ }^{\circ} \mathrm{C}\right.$ to c.a. $-140{ }^{\circ} \mathrm{C}$ ) is also effective. Over time, several cryopreservation techniques have been successfully applied with tomato pollen, seeds and shoot tips, including: slow cooling (not common anymore), desiccation, encapsulation-dehydration, droplet-vitrification and V-cryo-plate. Despite those studies reported high survival and no morphological variation of cryopreservation-recovered shoots, some differences between cryopreserved and noncryopreserved samples, revealed by biochemical, ultrastructural and molecular analyses, were observed. The intensity of those alternations was depending on the cell type, cultivar or plant generation. In the future, more attention could be focused on cryoprotection of embryogenic tissues and application of novel cryopreservation techniques, e.g. vacuum infiltration vitrification.
\end{abstract}

Keywords Biodiversity $\cdot$ Cryopreservation $\cdot$ Freeze-storage $\cdot$ Pollen $\cdot$ Seed $\cdot$ Shoot tip

Communicated by Daniel Sanchez Mata.

Dariusz Kulus

dkulus@gmail.com

1 Faculty of Agriculture and Biotechnology, Laboratory of Ornamental Plants and Vegetable Crops, UTP University of Science and Technology in Bydgoszcz, Bernardyńska 6, 85-029 Bydgoszcz, Poland 


\section{Introduction}

The protection of biodiversity is important for the purpose of systematics research, species evolution understanding, as well as in breeding programs and food security (Yi et al. 2008). Tomato is one of the most important vegetable crops on the market (Fentik 2017). It is of enormous economic value reaching billions of dollars (Van Eck 2018). Unfortunately, this important species has experienced severe genetic bottlenecks (Bauchet and Causse 2012; Kulus 2018a). Constant striving to get a selection of genotypes which are of better quality to existing ones, driven by market demands, leads toward drastic reduction in the number of varieties and cultivars, i.e. genetic erosion (Cebolla-Cornejo et al. 2013). The modern cultivated tomato genetic variation is highly limited when compared with the rich reservoir present in its wild relatives (Bhattarai et al. 2016; Sahu and Chattopadhyay 2017). Therefore, sustainable use with simultaneous efficient preservation of the species gene pool is necessary (Albrecht et al. 2010).

Over time several attempts have been made in order to protect tomato genetic resources (Ebert 2012; Halmagyi et al. 2017). Traditional in situ and ex situ preservation are two complementary methods of biodiversity protection. Ex situ preservation is referred to genebanks, which include seed collections, in vitro tissue banks, cryopreservation and DNA libraries. Some of the major genebanks that hold tomato accessions include: the CM Rick Tomato Genetics Resource Center (TGRC), University of California in Davis, USA and the United States Department of Agriculture (USDA) or Plant Genetic Resources Unit at Geneva (PGRU), USA, as well as laboratories in the International Board for Plant Genetic Resources (IBPGR) network (Sharifova et al. 2013). Despite their important role, traditional genebanks face severe bottlenecks in preserving the biological diversity (revived by Bauchet and Causse 2012). Recent tremendous discoveries in the field of cryobiology, i.e. the influence of cryogenic temperatures on living organisms, shed new light and possibilities to the protection of plant genetic resources (Fig. 1).

The aim of this review is to summarize the information about low-temperature storage of tomato genetic resources, with particular attention focused on cryopreservation.

\section{Refrigeration of working and active seed collections}

Numerous genebanks worldwide store working and active collections of tomato seeds, which are frequently utilized by breeders in their crop improvement programs, at a temperature of $5-10{ }^{\circ} \mathrm{C}$ at $20 \% \mathrm{RH}$ (relative humidity) (Robertson and Labate 2006). Prior to storage, seeds are ultra-dried to a level of 5-8\% (lower and higher moisture contents are not effective) in a controlled environment. The seeds are stored in containers that should be air-tight, but not vacuum-sealed to avoid seed damage (Robertson and Labate 2006). In such conditions the metabolic activity of cells is reduced, which enables their preservation. Despite refrigerated collections allow for a short- or medium-term (few-year) storage of numerous accessions at reduced space (Robertson and Labate 2006; Gonçalves et al. 2008a, b), a significant depletion of tomato seeds from stored accessions is observed because of the intermittent viability testing, as well as for the regeneration of plants (Grout and Crisp 1995; Bauchet and Causse 2012). Due to regeneration of small samples from each accession, genetic drift and loss of alleles take place. Moreover, storage of seeds which are a product of genetic recombination, i.e. generative propagation, is not a genetic stability guarantee. Modern biotechnology techniques, based on cryogenics, can be more eligible for long-term preservation of tomato collections. 


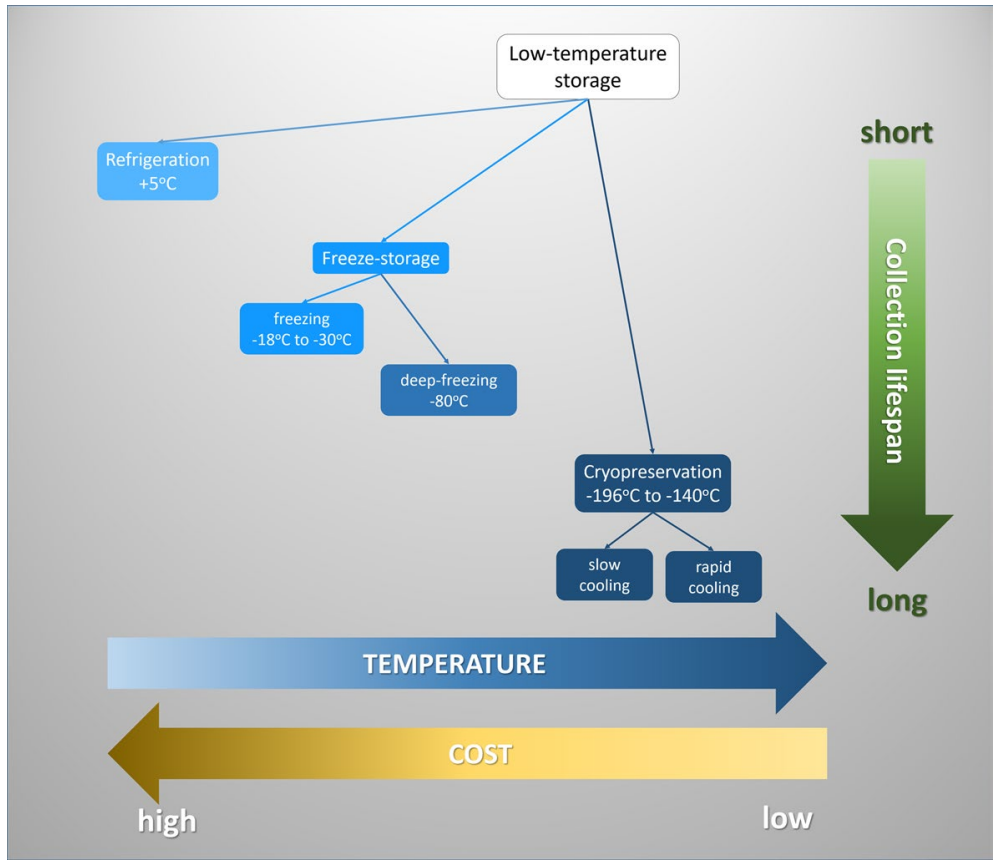

Fig. 1 Comparison of costs and efficiencies of various low-temperature storage methods. Working and active seed collections can be stored at $+5{ }^{\circ} \mathrm{C}$. The application of freezing and deep-freezing is rarely applied, mostly with pollen and seeds, due to problems with sample survival (intracellular lethal ice formation). Slow cooling is also no-longer common to use for cryopreservation of tomato germplasm because of high costs. Modern (rapid-cooling based) cryopreservation techniques, on the other hand, can be efficiently utilized for long-term storage of various biological materials

\section{Freeze-storage and cryopreservation}

Dry storage of tissues at sub-zero freezing temperatures or more popular cryopreservation in dewar flask at $-196{ }^{\circ} \mathrm{C}$ to $-140{ }^{\circ} \mathrm{C}$ (cryogenic temperatures), are complementary methods of long-term tomato germplasm preservation (Halmagyi et al. 2017). Preservation at $-20{ }^{\circ} \mathrm{C}$ (freezing) or $-80{ }^{\circ} \mathrm{C}$ (deep-freezing) requires special laboratory freezers, especially the latter approach. Moreover, plant tissues are very difficult to survive in such conditions. Consequently, these types of storage are not common. On the other hand, maintenance of biological material at cryogenics is power-independent (eco-friendly) and cost-efficient, as liquid nitrogen (LN) is inexpensive in most countries (Ganeshan and Rajasekharan 2005). Storage can be performed in liquid nitrogen $\left(-196^{\circ} \mathrm{C}\right)$ or in its vapor phase (to c.a. $-140{ }^{\circ} \mathrm{C}$ ). Maintaining specimens in the vapor phase is more problematic and less safe (due to possible temperature fluctuation) than immersion in the liquid phase, therefore, with tomato the former one is not used.

The survival of plant material at cryogenic temperature is possible (after proper optimization, as explained below) since the metabolic and physiological activity of the cells is greatly reduced; almost nil (Kulus and Zalewska 2014). Moreover, explants are stored in a small volume (a 2-ml cryovial may contain even 50 tomato seeds), protected from contamination (despite LN can be scarcely contaminated with pathogenic spores, they cannot 
penetrate the cryovial and the explant in such low temperatures), and require very limited maintenance (except for controlling the level of LN, as it is rapidly evaporating). As a result, tomato germplasm can be cryostored theoretically indefinitely, although this is difficult to prove (FAO 2014).

\section{History of cryopreservation}

The possible value of low temperatures on living organisms was suggested more than 300 years ago by a British physicist and chemist, Sir Robert Boyle (1665). However, those first experiments with preserving quite complicated biological systems and "touching cold" were completely unsuccessful and discouraging. The history of cryobiology began on April 13, 1883, when two Polish physicists, Zygmunt F. Wróblewski and Karol Olszewski liquefied nitrogen at the Jagiellonian University in Cracow. About one decade later, Sir James Dewar invented the vacuum flask (the so-called Dewar flask) for the storage of liquefied gases (Tilden 2009). At the beginning of the twentieth century, it was suggested that ice is the primary cause of cell death at subzero temperatures. This is because ice crystals, which have a greater volume than water in liquid phase, are bursting the cells. To solve this problem, in 1937 Basile Luyet proposed vitrification, i.e. transition of extra- and intracellular liquids into a highly viscous, semi-equilibrium amorphous glass state without ice crystal formation when the temperature is decreased, as a method for the cryopreservation of biological materials (Luyet 1937). However, obtaining this glass state was not simple. In 1948, C. Polge, A. U. Smith, and A. S. Parkes accidentally discovered (due to mismatch in the labeling of a bottle) the ability of glycerol to protect fowl spermatozoa from freezing injury at $-70{ }^{\circ} \mathrm{C}$ (Polge 1957). The recognition of cryoprotectants (or cryoprotectors), i.e. protective agents, such as: sucrose, glycerol, dimethyl sulfoxide (DMSO) and ethylene glycol (EG), was a milestone contributing to a wide application of cryopreservation (Pegg 2002). In the $50 \mathrm{~s}$, Dr. James Lovelock suggested that secondary cell damage during cryopreservation is caused by osmotic pressure, and further research should focus on avoiding this phenomenon. In 1963, Peter Mazur (Oak Ridge National Laboratory, U.S.) demonstrated that intracellular freezing can be avoided if cooling is slow enough to permit sufficient water to leave the cell during progressive freezing of the extracellular fluid-the so-called freeze-dehydration (Mazur 1963). After reaching a certain terminal temperature, further rapid freezing to cryogenics is possible. This discovery has led to the development of the first successful cryopreservation technique, known as the two-step freezing or slowcooling. Vitrification of plant specimens, however, can be succeeded in numerous ways. During the past three decades, the transport of cryoprotectants into and out of cells and tissues, as well as the behavior of water during freezing/thawing cycles became sufficiently well understood and several cryopreservation techniques were developed also for tomato. Cryobiologists have moved from the primary slow-cooling strategy, to an easier, cheaper and more efficient approach based on a vitrification through ultra-rapid cooling - the direct immersion of explants in LN. This became possible in 1990 when Prof. Akira Sakai and co-workers developed the so-called plant vitrification solution (PVS2) to preserve the nucellar cells of navel orange (Sakai et al. 1990). It is an optimized mixture of commonly used cryoprotectants (30\% glycerol w/v, 15\% ethylene glycol w/v, 15\% DMSO w/v, and $0.4 \mathrm{M}$ sucrose). PVS2 easily supercools below $-100{ }^{\circ} \mathrm{C}$ upon rapid cooling and 'solidifies' into a metastable glass at about $-115^{\circ} \mathrm{C}$. A range of alternative vitrification solutions have also been reported in the following years. In 1993, Nishizawa et al. (1993) developed the PVS3 (50\% glycerol w/v and 50\% sucrose w/v), which can be preferred for explants 
that are damaged by DMSO. In 1990, Fabre and Dereuddre developed a synthetic seedbased encapsulation-dehydration cryopreservation procedure for Solanum phureja Juz. \& Bukasov, which does not require the application of concentrated (and toxic) cryoprotectors. In this approach, the explants are embedded in gel matrix (calcium alginate) and, then, dehydrated. Combination of vitrification with encapsulation (Matsumoto et al. 1995), and the development of droplet-vitrification technique for solanaceous species (during the procedure explants are placed on aluminum foil strips prior to storage in LN) made cryopreservation even more efficient (Pegg 2002). Recently, the development of cryo-plate techniques (originally described by Yamamoto et al. 2011 and Niino et al. 2013) with tomato have also been reported (Al-Abdallat et al. 2017).

The potential of LN has been successfully utilized with numerous plant species, including ornamentals, fruit and vegetable crops (Condello et al. 2011; Kulus and Zalewska 2014; Zhang et al. 2014). As for the Solanceae family, cryopreservation has been widely applied with potato (Keller and Dreiling 2003; Edesi et al. 2015, 2017), but also with pepper and eggplant (Belletti et al. 1990). The first reports on cryopreservation of Solanum genus came from Grout and Henshaw (1978). They reported successful regrowth of Solanum goniocalyx shoot tips after cryoprotection with $10 \%$ DMSO followed by ultra-rapid cooling in LN. With S. tuberosum 'Agria' and 'Morphona' a highly efficient cryopreservation protocol with high survival and 97-100\% genetic homology of the LN-recovered plants with the untreated control was reported (Zarghami et al. 2008). Despite cryopreservation of tomato genetic resources seems a reasonable complementary preservation method, a limited number of publications is yet available. However, this technology will probably expand in the nearest future. First reports on the survival of tomato explants stored in liquid nitrogen come from Grout et al. (1978). Up to date, few cryostorage protocols on pollen, seed and shoot tips of wild and cultivated S. lycopersicum exist (Table 1).

\section{Pollen freezing and cryopreservation}

Pollen which is a product of genetic recombination, an event that takes place during microsporogenesis (pachytene/meiosis I) in angiosperms, presents great potential to release diversity at the gametophytic/haploid stage. However, only a very small portion of the produced in excess tomato pollen grains are actually involved in natural pollination. The remaining pollen produced by the crop is lost to nature; a genetic erosion operating at haploid stage (Ganeshan and Rajasekharan 2005). Therefore, there is a scope for preserving genetic diversity released in the form of pollen or even entire anthers. The natural pollen longevity of several tomato species (including S. lycopersicum, S. hirsutum, S. peruvianum and S. pimpinellifolium) is shorter in comparison to other plant species (e.g. Typha spp.). Pollen grains of tomato stored in open air lose half of their original germination capacity within only 2 days at $25{ }^{\circ} \mathrm{C}$ and within 5 days at $6{ }^{\circ} \mathrm{C}$, but their longevity can be prolonged to at least 6-9 years in sub-zero conditions with no reduction in viability and fertility levels (Ganeshan and Rajasekharan 2005; Song and Tachibana 2007). Besides long-term storage in a minimum of space, low-temperature storage of pollen facilitates the timing of crosses (by overcoming flowering asynchrony) and allows to overcome geographical/seasonal restrictions. Therefore, it can be successfully utilized to produce tomato seeds in the absence of fresh pollen (Alexander and Ganeshan 1989). 


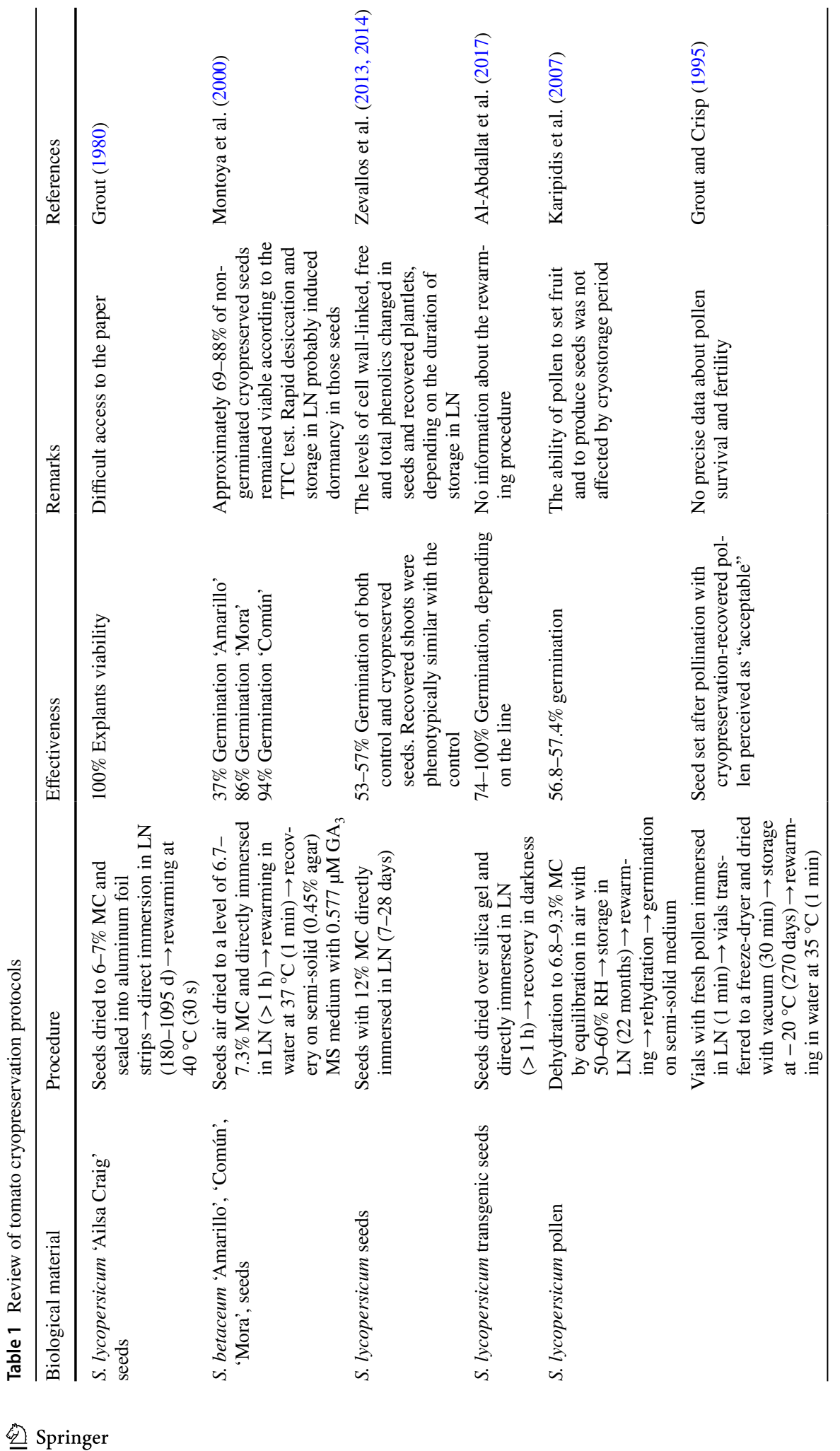




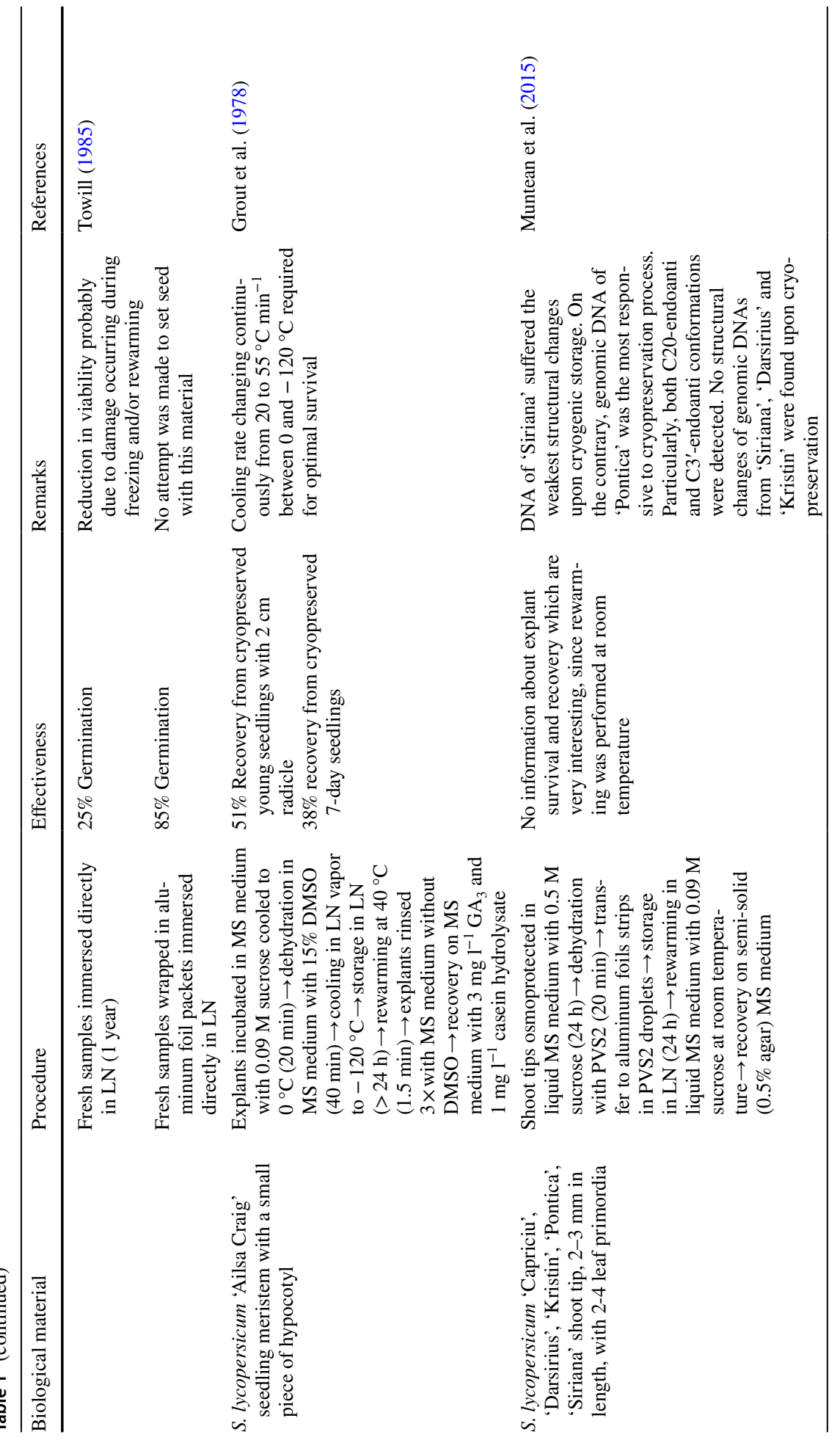




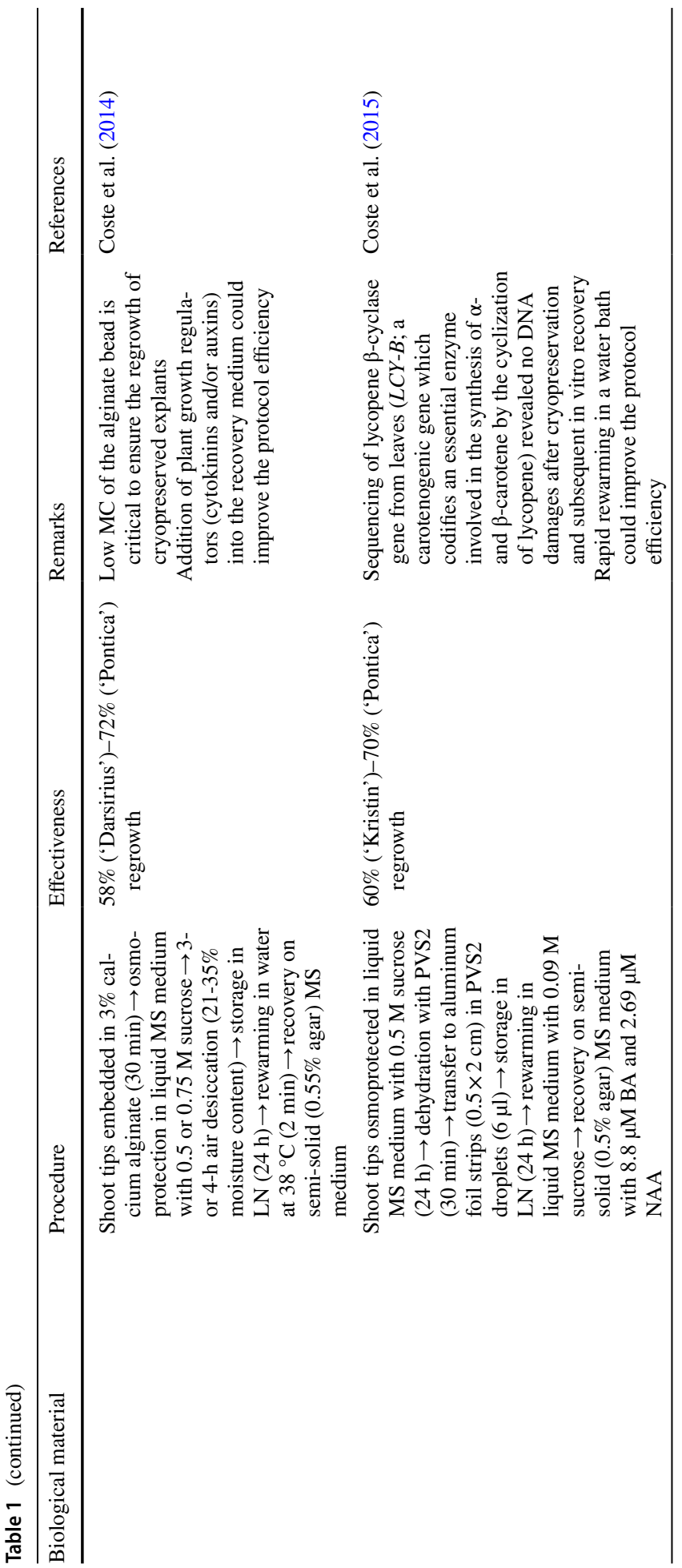




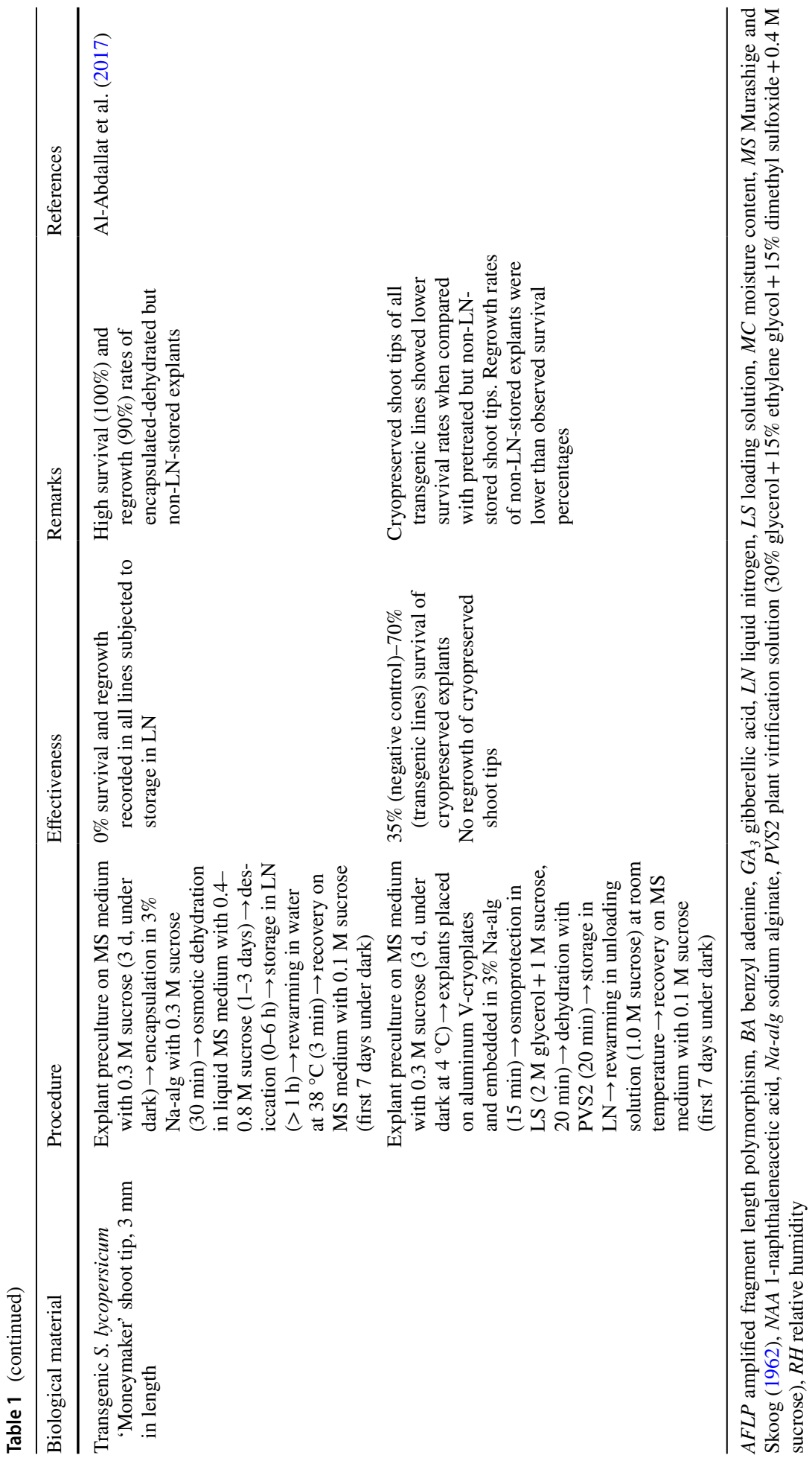




\section{Pretreatment}

Thermodynamic studies revealed that free (freezable) water removal is the most essential step in every protocol of tomato sub-zero temperature preservation. Since tomato pollen consists of relatively homogenous tissues with low moisture content, it is suitable to develop simple (drying-based), but efficient low-temperature storage procedures. In order to prepare the samples and facilitate handling, collected (with the aid of an electric tootsbrush) tomato pollen is embedded in gelatin capsules or paper pouches or packed on a paper strip. Next, the biological material is desiccated in air-tight glass tubes with anhydrous calcium sulfate $\left(\mathrm{CaSO}_{4}\right)$ or calcium chloride $\left(\mathrm{CaCl}_{2}\right)$ desiccant, either overnight at $4{ }^{\circ} \mathrm{C}$ to $6.5-7 \%$ (wet weight basis) or immediately stored at $-20 /-80 /-196{ }^{\circ} \mathrm{C}$ (Sacks and St. Clair 1996; Karipidis and Douma 2011).

\section{Freeze-storage}

Towill et al. (1985) reported increased (by 26\%) tomato pollen germination after storage at $-20{ }^{\circ} \mathrm{C}$ for 3 years as compared with the fresh control. This uncommon phenomenon has been attributed to an after-ripening process or the release of a needed, and previously compartmentalized, nutrient. In general, however, despite freezing temperatures $(-20$ to $-30{ }^{\circ} \mathrm{C}$ ) can be applied with tomato pollen, they are less efficient than deep-freezing or cryogenic storage, due to the reduced capacity to enhance gene translation for polyamine biosynthetic enzymes, i.e. arginine decarboxylase (ADC) and S-adenosylmethionine decarboxylase (SAMDC), upon rehydration. Also the capacity to synthesize proteins declines with the increase in freeze-storage duration (Song and Tachibana 2007). For example, tomato pollen showed normal germinability for at least 12 months in storage at $-30{ }^{\circ} \mathrm{C}$, but that stored for longer than 24 months exhibited a significant reduction in germinability and fruit-setting ability (Song and Tachibana 2007). Higher temperatures are even less efficient. According to Karipidis and Douma (2011), during storage at $-20{ }^{\circ} \mathrm{C}$ tomato pollen grain maintains high in vitro germination for 10 months. However, after only 6 months at $-20{ }^{\circ} \mathrm{C}$, pollen respiration activity and tube length declines with a negative influence on its fertility, as indicated by the reduced number of seeds in fruits obtained by artificial pollination. Similarly, Sacks and St. Clair (1996) reported that after 12 months of storage at $-20{ }^{\circ} \mathrm{C}$, tomato pollen germination ability decreases. On the other hand, identical pollen samples, which were stored at $-80^{\circ} \mathrm{C}$ for 10 months, with or without $20 \mathrm{~h}$ precooling at $+4{ }^{\circ} \mathrm{C}$, or repeatedly cooled to $-80{ }^{\circ} \mathrm{C}$ and rewarmed for even six cycles, continuously remained the same fecundity as the fresh pollen (measured by fruit set and number of viable seed per fruit).

The adverse effects of freezing temperatures can be reduced by the addition of $1 \mathrm{mM}$ putrescine, spermidine, or spermine to the recovery medium (Song and Tachibana 2007). The efficiency of freeze storage can also be improved by pretreating the samples with LN. King (1965 cited in Grout and Crisp 1995) developed a freeze-drying storage method based on prefreezing of fresh tomato pollen by immersion of the vials containing the biological material in LN. After 1 min, the material was transferred to a conventional bench-top freeze-dryer and dried with $30 \mathrm{~min}$ of vacuum, and then stored at $-20{ }^{\circ} \mathrm{C}$. After 2 years it was still capable of seed set, however, at a reduced recovery level. 


\section{Cryopreservation}

Despite it is a relatively new technology, the data suggest that cryopreservation of tomato pollen grains can facilitate efficient plant breeding. S. lycopersicum pollen stored at $-196{ }^{\circ} \mathrm{C}$ for 18 months presents similar in vitro germination, respiration activity and pollen tube growth as the fresh specimens. Moreover, artificial pollination with cryogenically stored pollen results in similar fruit set and number of seeds per fruit to those observed after pollination with fresh tomato biological material (Karipidis and Douma 2011). Pre-freezing (at $-25{ }^{\circ} \mathrm{C}$ ) can increase the viability of tomato pollen stored in liquid nitrogen. Also pretreatment in vacuum environment $(250 \mathrm{mmHg})$ acts positively in tomato pollen cryopreservation (Shuren et al. 1993).

\section{Recovery}

After rewarming, tomato pollen should be rehydrated for $3 \mathrm{~h}$ at $100 \% \mathrm{RH}$ and $15{ }^{\circ} \mathrm{C}$, and incubated for $6 \mathrm{~h}$ on semisolid substrate for recovery (1\% agar, 12\% sucrose and $50 \mathrm{mg} \mathrm{dm}^{-3}$ boric acid- $\mathrm{H}_{3} \mathrm{BO}_{3}$ ) (Karipidis and Douma 2011). Next, the biological material is shed from capsules, pouches or strips and maintained at $15-25^{\circ} \mathrm{C}$. Evaluation of tomato pollen viability can be performed by several methods: (1) in vivo-by placing the pollen on the stigmas of emasculated flowers and determining the number of seeds in the produced fruit, (2) in vitro-by analyzing pollen germination and pollen tube growth (expressed as percent normal and percent total germination, i.e. abnormal and normal-appearing grains), (3) histochemical, and (4) by analyzing the rate of respiration (Abdul-Baki 1992; Karapanos et al. 2010). Histochemical analysis based on inoculation of samples on a germination medium containing $0.29 \mathrm{M}$ sucrose, $1.27 \mathrm{mM} \mathrm{Ca}\left(\mathrm{NO}_{3}\right)_{2}$, $0.16 \mathrm{mM} \mathrm{H}_{3} \mathrm{BO}_{3}$, and $1 \mathrm{mM} \mathrm{KNO}$ ( $\mathrm{pH}^{5.2}$ ) and observation of tube growth; supported by pollen staining with $0.001 \%$ fluorescein di-acetate (FDA), triphenyl tetrazolium chloride (TTC) or Alexander dye composed of $95 \%$ alcohol, malachite green (1\% solution in $95 \%$ alcohol), distilled water, glycerol, fuchsine acid (1\% solution in water), Orange $\mathrm{G}$ ( $1 \%$ solution in water) and glacial acetic acid; is the most popular technique applied with tomato. By those means pollen viability is assessed within $30 \mathrm{~min}$ by determining the percent of fluorescing pollen in a sample, while pollen tube growth can be evaluated within 1.5 h (Abdul-Baki 1992; Paupière et al. 2017).

Cryopreservation of biological diversity in the form of pollen might lead to establishing pollen cryobanks serving as male gametophytic inputs for breeding new tomato cultivars or as a source of haploids/dihaploids, which are crucial in heterosis breeding and hybrid seed production (Tamta and Singh 2017). Cryopreserved pollen can be also a source of genes important to molecular biologists for synthesizing DNA sequences via biotechnological methods and for such manipulations (Ganeshan and Rajasekharan 2005).

\section{Seed freezing and cryopreservation}

According to FAO (2014), most valuable tomato accessions and safety duplicate samples should be stored under long-term conditions (base collections) at sub-zero temperatures. The seeds selected for storage should be well-developed, but with no signs of germination, i.e. embryo parts breaking the testa. 
Tomato seeds usually do not undergo maturation drying, and the mature seed water content is high (40\%), which is a characteristic of fleshy fruits (Berry and Bewley 1991). Therefore, the sole requirement for successful long-term preservation is drying in a stream of air or over silica gel to a level between 5.5 and $18.5 \%$ prior to storage. Lower water content reduces the seeds viability, whereas above $18.5 \%$ moisture, the High Moisture Freezing Limit makes low-temperature preservation unsuccessful (Grout and Crisp 1995). One should keep in mind, though, that water content, and the life span of stored accessions, can vary greatly (by over 300\%) in tomato seeds from the same locality from year-to-year, and also for material from the same locality, within any one season (FAO 2014). Prestorage temperature and the pace of drying have a vital effect on the seeds longevity (Walters et al. 2004). Faster drying is possible at higher temperatures, but the risk for physiological aging is reduced by lower drying temperatures (FAO 2014). Walters et al. (2004) observed that lowering gradually the storage temperature increases the tomato seeds longevity. As soon as the seeds have reached the optimal moisture content, they should be packaged and stored (FAO 2014).

\section{Freeze-storage}

Similarly to pollen, orthodox tomato seeds, i.e. seeds which will survive drying and/or freezing during ex situ conservation, can be stored at freeze temperatures in hermetically sealed containers for years, without any loss of viability or genetic integrity. It is essential that during storage the samples are sealed into dedicated packets or vials, and that these are then held in plastic boxes with lids to prevent them from picking up moisture from the atmosphere (Walters et al. 2004). Adequate containers can maintain desired moisture levels for up to 40 years, depending on the quality of the seal and the ambient $\mathrm{RH}$ at the genebank location (FAO 2014). Tomato seeds store well without major mutation for over 30 years at $-18{ }^{\circ} \mathrm{C}$ (Robertson and Labate 2006). With time, however, a decrease in viability and/or deterioration in performance of seed populations stored under freezing conditions is eventually observed. This is a result of the thermal behavior of the lipids, and visco-elastic properties of the tomato specimens, as well as their biochemical activity (e.g. free radical activity) which, although slowed, is not completely inhibited (Grout and Crisp 1995). Storage in LN can overcome those problems.

\section{Cryopreservation}

The relatively small tomato seeds can be cryopreserved without sophisticated pretreatment, required for more differentiated tissues (Grout and Crisp 1995). They are described as both desiccation and LN tolerant. Up-to-date, seeds of several tomato cultivars were successfully stored in LN. Storage periods ranging from 180 to 1095 days resulted in germination rates of $99 \%$ when water contents were below $7.2 \%$ of initial wet weight. If the moisture content was at $8.7 \%$, the germination rate of rewarmed seeds fell to $84 \%$ (Grout and Crisp 1995). Grout (1980) reported $100 \%$ viability of tomato seeds, at a water content of 6-7\% fresh weight, which were sealed into aluminium foil packets, and then directly immersed in LN. Subsequently, samples were rewarmed by placing the packets in a water bath at $40{ }^{\circ} \mathrm{C}$ for $30 \mathrm{~s}$. In this experiment the high thermal conductivity of aluminum was utilized. By those means a vital ultrarapid cooling rate, measured in the cotyledonary tissues, of $940{ }^{\circ} \mathrm{C} \mathrm{min}^{-1}$ and a rewarming rate in excess of $700{ }^{\circ} \mathrm{C} \mathrm{min}^{-1}$ were achieved. On the other hand, Montoya et al. (2000) found that 
69-88\% of cryopreserved seeds remained viable, but did not germinate after storage in LN. If drying is not possible, the efficiency of a cryopreservation protocol can be improved by proper pretreatment of the seeds with cryoprotectants. For example, Grout and Crisp (1995) reported a $100 \%$ viability or cryopreserved tomato seeds with a high moisture content (exceeding 27\%) after earlier pretreatment in $15 \%(\mathrm{v} / \mathrm{v})$ aqueous solution of DMSO for $1 \mathrm{~h}$.

Cryopreservation reduces the urge of specimens regeneration, which is required in traditional seed banks, as well as viability monitoring. It is assumed that once immersed in LN, explants should not change beyond the physiological point at which they were placed in cryostorage ad infinitum. For example, Zevallos et al. (2013) reported that LN exposure increased the percentage of wild S. lycopersicum seed germination at 5 days after rewarming when compared with the untreated-control, as immersion in LN probably helped break seed dormancy. However, after 7 days, the conversion into plantlets and the plant fresh mass were not different between non-cryopreserved and LN-stored samples. One should keep in mind though, that the effect of timescales on cryopreserved explant viability has not been tested, either theoretically or empirically (Zevallos et al. 2013). According to Walters (2004), molecular mobility in the cytoplasm of tomato seeds could still occur even at cryogenic temperatures, depending on water status. This molecular mobility may induce oxidative stress through the formation of free radicals, which may (micro)fracture the cell membrane system (Zevallos et al. 2013). Still, according to Pritchard (1995), tomato seed longevity at $-196{ }^{\circ} \mathrm{C}$ could be about 175 times higher compared to that achieved at $-18{ }^{\circ} \mathrm{C}$, whereas Coste et al. (2015) predict that seeds can survive for hundreds of thousands of years under cryogenic conditions (compared to $100-200$ years at $-18{ }^{\circ} \mathrm{C}$ ). Al-Abdallat et al. (2017) reported even an increased germination capacity (by $24 \%$ ) of cryopreserved seed when compared to the untreated control. This, however, is not a common phenomenon.

A drawback of using seeds in cryostorage is their heterogeneity, defined as the production of different types of seeds by a single individual, observed especially within wild tomato species (Zevallos et al. 2013). This heterogeneity may occur in seed size, shape, color, and also physiological properties, which affect germination and longevity behaviors (Matilla et al. 2005). In consequence, cryopreserved tomato seeds showed lower germination percentages compared to some other plant species (Zevallos et al. 2013). Therefore, the importance of the origin of the seeds employed in cryopreservation should be highlighted.

\section{Cryopreservation of in vitro-derived tomato explants}

Plants recovered from vegetative tissues are more genetically uniform than those produced from seeds. In addition, in vitro-grown tomato plantlets are available any time of the year. Therefore, in vitro-derived explants also seem accurate for the purpose of tomato long-term storage.

Cryopreservation of differentiated tissues with high initial water content is more complex than of seeds or pollen. Obtaining a 100\% survival of the cryopreserved tomato shoot tips, which are most commonly used, is rather unlikely. Therefore, cryopreservation attempts must be preceded with clonal in vitro propagation of a sufficiently large pool of microshoots. This involves appropriate surface disinfection procedures and medium preparation. Fortunately, with tomato these procedures are well described. 


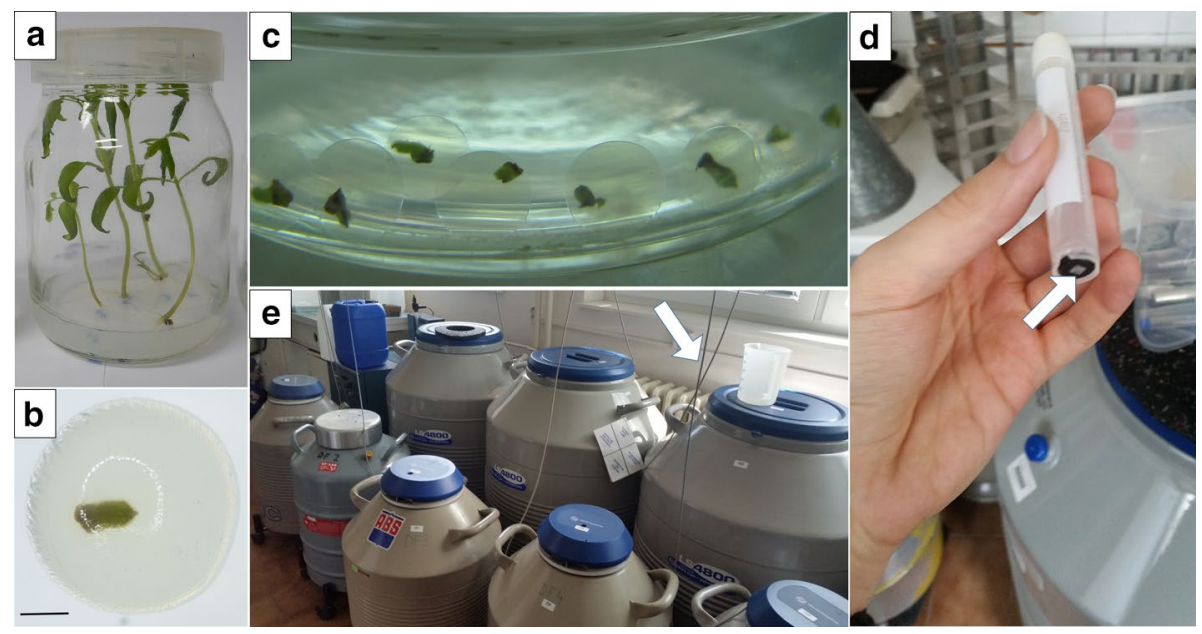

Fig. 2 Cryopreservation of tomato. a Preconditioning of microshoots on a sucrose-enriched medium. b Tomato shoot tips encapsulated in calcium alginate. c Osmotic dehydration of encapsulated tomato shoot tips in a liquid MS medium with $1.0 \mathrm{M}$ sucrose. d Modern cryovials have a chip implanted at the bottom (indicated with an arrow) for easier sample identification. e Today's smart technology allows for the application of electronical probes in dewar flasks (indicated with an arrow), which transmit data about the LN level or unsealing of the vessel to an application on a mobile phone/computer; $b a r=1 \mathrm{~mm}$

\section{Disinfection and multiplication}

It is easy to initiate an aseptic tissue culture from tomato seeds by surface disinfection with 75\% Clorox (active chlorine content 5\%) for $15 \mathrm{~min}$ and rinsing three times with sterile distilled water, followed by germination on a half-strength MS medium, pH 5.7 (Coste et al. 2014). A similar protocol, based on surface disinfection of seeds with $3 \%$ sodium hypochlorite for $5 \mathrm{~min}$ and $70 \%$ (v/v) ethanol solution for $30 \mathrm{~s}$, was described by Al-Abdallat et al. (2017). Next, the plantlets can be easily and rapidly cloned in vitro. As for tomato, a species exhibiting high apical dominance, the single-node technique on a PGRs-free MS medium is sufficient, although faster and more efficient micropropagation rate can be achieved after adding $8.88 \mu \mathrm{M}\left(2.0 \mathrm{mg} \mathrm{dm}^{-3}\right) \mathrm{BA}$ and $2.69 \mu \mathrm{M}\left(0.5 \mathrm{mg} \mathrm{dm}^{-3}\right)$ NAA.

\section{Principles of successful cryopreservation}

In order to prepare the explants for a shock associated with the exposure to cryogenic temperatures and further rewarming, several steps require consideration, including: (1) explant selection, (2) preculture and/or pretreatment, and (3) post-storage recovery (Fig. 2). All of the above steps should be carefully optimized to protect the cell from cryoinjury and enable their successful rehydration and recovery, whenever needed.

(1) Explant selection The physiological state, as well as physical and biochemical parameters of samples before they are stored in LN has a strong impact on the cryobanking success. The origin, mass, geometry and cell anatomy of the tomato explant, as well as permeability characteristics of the tissue are all determining cryoprotectant diffusion into the intercellular spaces and cells of tissues, and therefore, the success of the entire protocol (Grout and Crisp 1995; Muntean et al. 2015). Explants selected for cryopreservation should be of possible best quality—young, healthy, and vigorous (Grout et al. 1978). 
Heterogeneity in morphology, physiology and cellular chemistry of tissues can hamper successful cryopreservation. For example, Grout et al. (1978) reported that explants dissected from young tomato seedling are more suitable than older and more developed ones. This is because stress-related fractures (associated with cooling/rewarming cycles) usually occurring in composite tomato organs are less typical in meristems and cell suspensions (Zevallos et al. 2013). It should be emphasized tough, that tomato root tips are more affected by cryostorage compared with shoot meristems (Zevallos et al. 2013). This is due to $S$. lycopersicum radicles having a great volume of cortical and pith parenchyma cells, which generally are much more vacuolated than meristematic cells, and are therefore, susceptible to cryoinjury. Similarly in shoot tips, most of the ultrastructural changes after cryoprotection with PVS2 were observed in the corpus (L3), but not in the tunica (L1, L2) layers. Shortly after rewarming, tomato tunica cells; which survival is essential for the further shoot development; displayed a regular structure with dense cytoplasm, while in basal corpus cells high vacuolation and signs of plasmolysis were observed (Halmagyi et al. 2017). Therefore, it is recommended to use tomato shoot tips, which are as small as possible, however, big enough to be able to develop after excision and rewarming (FAO 2014). One should also keep in mind, that the cryopreservation efficiency may be cultivar or even genotype specific, as reported by Coste et al. (2014, 2015).

(2) Preculture After selection, tomato explants must be properly prepared and hardened for stress. Suitable media and conditions for in vitro growth of explants need to be developed starting with a solid MS medium (Murashige and Skoog 1962) with some modifications (FAO 2014). Increase of sucrose level in the preculture medium is essential with tomato shoot tips, by enhancing their resistance to dehydration and liquid nitrogen exposure (Coste et al. 2015). Sucrose stimulates osmotic pressure that minimizes the rapid movement of water, and is engaged in the formation of the biological glass. For example, no shoot recovery was found after using the droplet-vitrification technique (sole pretreatment of tomato shoot tips with PVS2 prior to storage in LN on aluminum foil strips), whereas applying an additional preculture on MS medium with $0.5 \mathrm{M}$ sucrose elevated the results to even $70 \%$. On the other hand, sucrose concentration higher than $0.5 \mathrm{M}$ has an unfavorable effect (osmotic shock) on the species shoot tips survival and recovery rates after cryopreservation, as observed by Coste et al. (2014, 2015).

Manipulation of physical conditions, such as light and temperature regimes during preculture may also influence the explant stress-resistance. For instance, lowering the temperature to $4{ }^{\circ} \mathrm{C}$ during a 3-day preculture elevated the cryopreserved tomato shoot tips survival form 35 to $75 \%$ (Al-Abdallat et al. 2017). A typical preculture of tomato explants lasts form one (Muntean et al. 2015) to 3 days (Al-Abdallat et al. 2017), depending on the protocol and genotype.

Pretreatment (dehydration) Dehydration can be achieved in several (chemical and/ or physical) one- or multi-step ways. Chemical dehydration is performed with the use of cryoprotectors. They are replacing cellular water, increasing cell viscosity, and altering the freezing behavior of the remaining intracellular (non-freezable) water by lowering its freezing point (Engelmann 2014). Cryoprotectants are divided into two groups: non-penetrating (sucrose and other carbohydrates) and penetrating the cell (e.g. DMSO, EG). Despite the penetrating cryoprotectants are more efficient, however, they are also more toxic. Therefore, in order to protect the cells from the adverse effect of concentrated PVS, the tomato explants are first osmoprotected (loading treatment) for 20 min with a loading solution (LS), which is a mixture of low-concentrated, non-penetrating cryoprotectors; usually $2 \mathrm{M}$ glycerol and 1.0 M sucrose (Coste et al. 2015; Al-Abdallat et al. 2017). 
Physical (evaporative) dehydration, on the other hand, is performed either over a silica gel or in the stream of (sterile) air flow (Coste et al. 2014). The first approach is more rapid and easier to control, while the second one-less shocking and damaging to the tomato tissues.

By providing proper conditions, freezing is avoided and a glassy/vitreous state can be achieved, but toxic damage caused by the high concentrations of cryoprotectants is a critical problem (Pegg 2002). For example with five tomato cultivars, the cryopreservation efficiency increased with PVS2-exposure duration up to $30 \mathrm{~min}$, but declined after longer dehydration periods (Coste et al. 2015). Therefore, it is necessary to balance osmotic and cytotoxicity effects. The key points in developing an efficient protocol for cryopreservation of tomato shoot tips include the concentration of cryoprotectants and exposure time for osmoprotection and dehydration. Those parameters depend also on the ambient temperature. Therefore, treatment on ice is recommended when applying a PVS, especially for longer durations.

(3) Recovery of the tomato explants also requires proper action after storage in LN. Vitrified systems are instable during rewarming since changes in molecular mobility may allow the remaining water molecules to recrystallize, as observed by Al-Abdallat et al. (2017). Therefore, the LN-stored tomato samples should not be transferred to room temperature. Instead, the cryovials can be placed in a water-bath at $35-40{ }^{\circ} \mathrm{C}$ for 1-3 min in order to provide a high rewarming pace (shorter duration is preferred with vitrification and droplet-vitrification techniques, to minimize the toxic effect of PVS2 on the explant).

The possibility of producing in vitro whole plants from cryopreserved tissues is required. Recovery of cryopreservation-derived tomato shoot tips starts from a few days to about 3 weeks after rewarming, depending on the protocol, with an expansion of the first leaf (Coste et al. 2014; Halmagyi et al. 2017).

The applied recovery medium has to stimulate the direct development of tomato shoots, but at the same time, the formation of genetically instable callus or hyperhydrated/ deformed shoots should be avoided, which is not always an easy task. In $S$. habrochaites f. typicum (a species of high salt tolerance), merely inoculating the explants, i.e. cotyledon fragments, on the MS medium supplemented with benzyl adenine (BA) and 1-naphthaleneacetic acid (NAA) resulted in the abundant callus formation with altered genome (Rzepka-Plevneš et al. 2010). The callus genetic similarity to the plants regenerated by direct organogenesis was only $40 \%$, as determined by using Inter Simple Sequence Repeats (ISSR) markers.

Another problem is the reported sometimes divergence between the survival and recovery/regrowth rates. For example, Al-Abdallat et al. (2017) recorded that despite the survival of the cryopreserved transgenic tomato shoot tips reached even $70 \%$, however, no further recovery was possible. Therefore, careful plant growth regulators (PGRs) selection, and their concentration optimization, is required.

One should keep in mind tough, that hormonal regulation of tomato explants growth can be altered by the cryopreservation procedure. For example, Grout et al. (1978) reported that viable $S$. lycopersicum explants (cryopreservation-recovered shoot tips) produced shoots directly by typical meristem growth when cultured in the presence of gibberellic acid $\left(\mathrm{GA}_{3}\right)$ after rewarming. Without $\mathrm{GA}_{3}$, the surviving explants produced callus and, subsequently, adventitious shoots. On the other hand, non-cryopreserved plant material produced shoots directly without the requirement for $\mathrm{GA}_{3}$ addition. In order to enhance the uptake of PGRs, a semi-solid medium, with reduced by half agar concentration, can be applied at the beginning of the recovery culture (Coste et al. 2014, 2015). 
Survival evaluation is an important issue to make a fair assessment of a tomato cryopreservation protocol. Simple observation of the explant regrowth potential is the most reliable method. It may, however, take a few days or even weeks. Histochemical analysis is a faster approach. This technique is based either on the possibility to stain specific constituents of the tomato cell, or on the activity analysis of specific enzymes (Abdul-Baki 1992; Paupière et al. 2017). For example, iodine potassium iodide and aniline blue can be applied to stain tomato starch and other polysaccharides, phyloxin-methyl green to stain cell wall, and acetocarmine or safranin to stain ribonucleic acids and chromatin. Enzyme activity, on the other hand, is usually tested by the reduction of the tetrazolium group (TTC) to yield the colored insoluble formazans, or the hydrolysis of FDA by esterase to yield fluorescein (Abdul-Baki 1992; Hichri et al. 2017). One should keep in mind, though, that the histochemical analysis should be performed at least a few hours after rewarming of explants to make the results highly correlated to the survival of the biological material. Moreover, the staining media may have an adverse effect on the tomato cell viability and prevent its further development.

\section{Review of various cryopreservation techniques of tomato shoot tips}

Up-to-date three cryopreservation techniques were successfully applied with tomato shoot tips. These include: classical (slow-cooling), encapsulation-dehydration and droplet-vitrification.

\section{Classical method}

With tomato, shoot tips were the first to be used for cryopreservation via the so-called classical method (two-step freezing/slow cooling). According to Grout et al. (1978), explants were first incubated in MS medium with $3 \% \mathrm{w} / \mathrm{v}$ sucrose, and cooled to the temperature $0{ }^{\circ} \mathrm{C}$ for $20 \mathrm{~min}$ (no details given). Then, the shoot tips were subjected to 40 -min pretreatment with $15 \%$ DMSO, followed by cooling in vapor above liquid nitrogen (with a cooling rate changing from 20 to $55^{\circ} \mathrm{C} \mathrm{min}{ }^{-1}$; to the temperature $-120{ }^{\circ} \mathrm{C}$ ) prior to immersion in $\mathrm{LN}$. After rewarming, recovery on a $\mathrm{GA}_{3}$-supplemented medium guaranteed satisfying survival. In general, however, rapid cooling is more effective than slow cooling. For instance, no viable tissue was observed after slow cooling $\left(2{ }^{\circ} \mathrm{C} \mathrm{min}^{-1}\right)$ of tomato 'Ailsa Craig' shoot tips, whereas $52 \%$ of $\mathrm{LN}$-stored and rewarmed explants were capable of regeneration after a previous rapid cooling rate of $800{ }^{\circ} \mathrm{C} \mathrm{min}^{-1}$ (Grout et al. 1978).

\section{Encapsulation-dehydration}

Coste et al. (2014) optimized an efficient encapsulation-dehydration cryopreservation protocol of five tomato cultivars ('Capriciu', 'Darsirius', 'Kristin', 'Pontica' and 'Siriana'). Shoot tips with 2-3 leaf primordia (2-3 mm in length) were dissected from 1-month old microshoots. Next, the explants were embedded in standard 3\% calcium alginate (MS medium-based) for $30 \mathrm{~min}$. The beads were osmoprotected in liquid MS medium containing 0.5-0.75 $\mathrm{M}$ sucrose and desiccated in a laminar air chamber for 3-4 h (25-35\% initial bead water content). By those means a high $72 \%$ recovery of the rewarmed shoot tips was reported. Encapsulation of tomato explants did not affect their early growth (shoot formation reported already after 10 days in post-rewarming culture), although further shoot growth was slower in comparison with the non-encapsulated explants. The highest 
rhizogenesis efficiencies (58-77\%) for all cultivars tested were noticed for shoots grown on MS medium supplemented with $6.66 \mu \mathrm{M}\left(1.5 \mathrm{mg} \mathrm{dm}^{-3}\right)$ BA and $4.92 \mu \mathrm{M}\left(1.0 \mathrm{mg} \mathrm{dm}^{-3}\right)$ indole-3-butyric acid (IBA). On the other hand, the greatest number of roots was reported after adding $2.46 \mu \mathrm{M}\left(0.5 \mathrm{mg} \mathrm{dm}^{-3}\right)$ IBA. In vitro rooting of shoots was essential for ex vitro acclimatization. This final step (with typical light and relative humidity control) was fully successful, with a 90-100\% survival.

Also Al-Abdallat et al. (2017) applied the encapsulation-dehydration technique for transgenic tomato lines. Shoot tips were precultured into a MS solid medium supplemented with $0.3 \mathrm{M}$ sucrose for 3 days under dark conditions. Next, the explants were embedded in calcium alginate supplemented with $0.3 \mathrm{M}$ sucrose, osmotically dehydrated in $0.4-0.8 \mathrm{M}$ sucrose (for 1-3 days), and then desiccated for 0-3 h. After storage in $\mathrm{LN}$, the samples were rewarmed and transferred to a recovery MS medium supplemented with $0.1 \mathrm{M}$ sucrose. The cultures were kept for 7 days under dark conditions and then transferred to light. Maintaining the cultures in dark during the preculture and/or early recovery steps may improve the cryopreservation protocol efficiency, due to the reduced biosynthesis of phenolic compounds which could hinder the regrowth of the explants, and the elimination of the phototoxic effects. Unfortunately, no regrowth was observed in that study, regardless of the dehydration period.

\section{Droplet-vitrification}

A droplet-vitrification protocol for tomato shoot tips was described by Coste et al. (2015). The highest shoot recovery after cryopreservation was $60-70 \%$ following $24 \mathrm{~h}$ preculture in liquid MS medium with $0.5 \mathrm{M}$ sucrose, and then $30 \mathrm{~min}$ dehydration in PVS2. It is worth mentioning, that the same optimal pretreatment conditions were recorded for all five cultivars tested, which is not common with other plant species (Kulus and Zalewska 2014).

Muntean et al. (2015) developed another droplet-vitrification protocol for in vitro-grown shoot apices of five tomato cultivars. Explants, consisting of the meristematic dome with 2-4 leaf primordia (2-3 $\mathrm{mm}$ in length) were osmoprotected in liquid MS medium with $0.5 \mathrm{M}$ sucrose for $24 \mathrm{~h}$. Next, explants were dehydrated with PVS2 for $20 \mathrm{~min}$. Pretreated shoot apices were transferred to aluminum foil strips in PVS2 droplets and then directly immersed in LN. Despite the Authors call it successful, however, there was no information on the survival or recovery rates provided.

Based on the mentioned above examples it can be concluded that cryopreservation of meristematic tissues enables a long-term collection of valuable, characterized clones.

\section{Stability after cryopreservation}

Trueness-to-type of the recovered plant material is usually required, but Rzepka-Plevneš et al. (2010) observed that somaclonal variation can be easily induced in tomato regenerated from callus. Cryopreservation causes many stresses that could potentially affect the stability of plants or their cell structure. For example, osmoprotection of S. lycopersium 'Darsirius' shoot tips in $0.5 \mathrm{M}$ sucrose for $24 \mathrm{~h}$ did not alter significantly the cells structure, except for increased starch accumulation in both tunica and corpus layers (Halmagyi et al. 2017). Subsequent dehydration in the PVS2 for $30 \mathrm{~min}$, however, left traces (i.e. pronounced vacuolation, affected plastid shape and a less clearness of the subcellular structures) in some cells, especially in the basal corpus (L3) parts. According to Halmagyi et al. (2017), injuries occurring at cellular and subcellular level in tomato are not attributed to 
a single stress element (i.e. the excessive dehydration, the toxicity of cryoprotective substances or the freezing per se), but rather they may act cumulatively and become evident some time later. Therefore, before it is routinely used, the impact of cryopreservation on the cryobehavioral (post-rewarming) response and the stability of the stored tomato accessions should be considered.

Phenotypic evaluation of whole plants for morphological and agronomical parameters is one of the easiest and efficient methods to detect changes following cryopreservation. Moreover, molecular markers based on DNA fragments analysis, as well as biochemical markers were also applied with tomato plants reporting some very interesting results. The data obtained from Amplified Fragment Length Polymorphism (AFLP) analysis (four primer combinations) showed no genetic dissimilarities between plants recovered from droplet-vitrification-cryopreserved shoot tips compared with the non-cryopreserved controls, suggesting no impact of cryotreatment on the species stability (Coste et al. 2015). However, more than one marker type should be utilized in every analysis. A good example was provided by Zhang et al. (2014), who compared 35 morphological traits of tomato plants recovered from cryopreserved and non-cryopreserved tomato seeds. No differences were observed between those two groups, either in the first or in the second generation of plants. However, at the molecular level, 14 nuclear Simple Sequence Repeat (SSR) markers revealed some changes in microsatellite length between control and cryopreserved samples in the second generation of plants. This influence may not only be generation-, but also cultivar-dependent, as observed by Muntean et al. (2015). They performed surfaceenhanced Raman scattering (SERS) spectra of genomic DNAs from tomato plants of five cultivars prior and after cryobanking. It was found, that DNA isolated from S. lycopersicum 'Siriana' leaf tissues suffers the weakest structural changes upon LN-storage of shoot apices, whereas 'Pontica' is the most susceptible to variation.

Recent research showed also several significant effects of cryopreservation recorded at the biochemical level of wild tomato plants. Freezing injury induces the production of free radicals, mainly of reactive oxygen species (ROS), which attack the lipid fraction of membranes and affect the plant metabolism. Zevallos et al. (2013) reported that non-treated control and cryopreserved seeds for 7-21 days (previously dried to $12 \%$ initial moisture content) displayed identical, 55\% germination rate, and no phenotypic differences were observed in the recovered seedlings. However, the levels of cell wall-linked, free and total phenolics decreased significantly in roots, stems and leaves of cryopreservation-recovered plants. Moreover, the concentration of the mentioned above compounds generally increased when seeds were immersed in $\mathrm{LN}$ for 28 days compared to non-treated control. In another publication, Zevallos et al. (2013) recorded increased levels of peroxidase enzymatic activity and cell wall-linked phenolics in leaves of cryopreservation-derived Ecuadorian wild tomato plants. As for roots, decreased contents of chlorophylls and cell wall-linked phenolics were noticeable. Those changes in primary and secondary metabolites content are a result of abiotic stress which affects the activity of numerous enzymes (Zevallos et al. 2013). Such alternations can be important for the pharmaceutical industry. Therefore, further experiments based on various marker types are required to clarify potential effects of cryopreservation on the stability of stored tomato accessions.

\section{Future perspectives of tomato cryopreservation}

The described protocols here can be used for cryostorage of tomato genetic resources in genebanks worldwide. However, the implementation of cryopreservation as a routine 
preservation method is still limited, since it requires skillful manipulation and involves laborious steps, i.e. osmoprotection and dehydration treatments associated with the transfer of samples. Therefore, modern approaches, such as: V-cryo-plate and D-cryoplate methods should be considered for the preservation of tomato genetic resources (Al-Abdallat et al. 2017). The concept of those techniques is based on aluminum strips, containing several oval wells. The explants attached to the cryo-plates are then dehydrated. The V-cryo-plate is based on PVS-dehydration, while the D-cryo-plate method is based on air dehydration. The techniques facilitate handling of cryopreservation and rewarming procedures and minimize the risk of small explants loss or their mechanical injury. A common problem associated with mistiming solution exposure is also avoided. Both methods can ensure very high cooling and rewarming rates $>4000{ }^{\circ} \mathrm{C} \mathrm{min}^{-1}$ of treated tissues (Yamamoto et al. 2011; Niino et al. 2013). Up-to-date, only Al-Abdallat et al. (2017) made and attempt to optimize the V-cryo-plate cropreservation protocol with tomato. In their study, shoot tips $(\sim 0.3 \mathrm{~cm}$ length) were precultured at 4 or $25{ }^{\circ} \mathrm{C}$ for 1-3 days on a PGRs-free MS medium supplemented with $0.3 \mathrm{M}$ sucrose and incubated in the dark. After that, the precultured shoot tips were placed on aluminium V-cryo-plates and embedded in alginate gel. Osmoprotection was performed by immersing the cryoplates in LS (2 M glycerol + 1.0 M sucrose) for $20 \mathrm{~min}$. For dehydration, the cryoplates were immersed in PVS2 for additional $20 \mathrm{~min}$ at $25{ }^{\circ} \mathrm{C}$ prior to immersion in LN. Despite the survival rate of the pretreated, but not LN-stored samples was very high (90-100\%, irrespective to incubation time or cold hardening), the viability of the LN-stored shoot tips was much lower (20-70\%) and no further regrowth was recorded. The reason of this failure might have been attributed to improper optimization of the procedure; e.g. on the rewarming step, which was performed at room temperature (in $1.0 \mathrm{M}$ sucrose). It was found with other plant species that rapid rewarming in a water bath is more effective, as it prevents ice-recrystallization (Kulus and Zalewska 2014). Therefore, this technique still requires exploration with tomato.

Another novelty, which was not yet applied with tomato, is the vacuum infiltration vitrification (VIV) developed by Nadarajan and Pritchard (2014). The use of a vacuum during explant incubation in a cryoprotective agent allows for its increased penetration, and therefore, reduces the total protocol time. Another advantage of this technology is the reduction of temperature dependency for cryoprotectant application. VIV-cryopreservation also overcomes the problems of specimen heterogeneity (volume, mass, oil composition and thermal properties). Therefore, it is recommended to optimize this technique also for the tomato clade. There are also no reports on applying the encapsulation-vitrification technique (based on explant encapsulation followed by vitrification in PVS) with tomato, despite it was very successful with other plant species, also of the Solanum genus (Engelmann 2014).

An alternative approach can focus on the elevation of stress-tolerance associated with cryotreatment of tomato plants via transcriptional regulation of stress-tolerance genes. By those means a higher efficiency of cryopreservation procedures can be obtained. For example, transgenic S. lycopersicum plants overexpressing the stress-responsive transcription factor SIAREB1 showed better tolerance to severe osmotic stress conditions during a cryopreservation protocol, and higher survival and regrowth rates in comparison to the negative control (Al-Abdallat et al. 2017). Also more attention could be paid to the possibility of cryopreserving wild tomato relatives, especially their embryogenic tissues, i.e. proembryogenic masses, (somatic) embryos or their axes. The costs of a cryoprotocol (which are mainly related to in vitro steps prior and after storage in $\mathrm{LN}$ ) can be reduced by applying less expensive substitutes and cheaper technological fix (Miler et al. 2018). 
Another issue that should be considered, is the possible epigenetic variation caused by cryopreservation procedures. It was in fact observed with numerous plant species, that despite cryopreservation does not cause any significant genetic perturbation, however, alternations in cytosine methylation are quite common (Kulus and Zalewska 2014).

In order to ensure sustainable and practicable use of cryopreservation, comparative detailed validation of methods between different laboratories, economic analyses and efficient integration strategies of cryobanks by genebanks; including safe duplication of cryopreserved resources in vitro or in the field; are recommended (Keller et al. 2008). At the same time, at least one subsample of any tomato accession should be stored in $\mathrm{LN}$, in addition to the samples stored under conventional genebank or in situ conditions.

\section{Conclusions}

A significant erosion of the existing genetic diversity of S. lycopersicum is observed (Kulus 2018b). A large number of old cultivars and landraces of small/irregular fruits, which represent the original genetic diversity, have been lost. The reason of this can be explained by a founder effect, selfing, natural and artificial selection (especially in the past 80 years) with the recent trend towards breeding cultivars of similar plant and fruit characteristics (Archak et al. 2002; Cebolla-Cornejo et al. 2013; Giovannoni 2018). Therefore, the urgent and prompt action is necessary to preserve the tomato genetic diversity. Nowadays, sub-zero temperature storage is considered to be the most efficient technology of biodiversity protection. A critical objective of this approach is to reduce the frequency of samples regeneration by maximizing their longevity, thereby diminishing the costs of genebanking (FAO 2014). Freeze-storage is quite successful, although limited to tomato seeds and pollen, while cryopreservation is a reliable complementary approach.

Cryopreservation can be utilized for the ex situ preservation of tomato genetic resources, aiding food security and protection of cultivars/varieties from diverse habitats and at risk of extinction. Cryopreserved lines can be maintained as a backup for field collections, as reference collections for available genetic diversity, and as a source for new alleles in the future breeding programs (FAO 2014). Despite this high throughput technology seems effective, still a lot of work is required for tomato as no protocols are routinely applied. Cryopreservation is determined by a complex interaction of numerous factors which require careful optimization. The impact of liquid nitrogen exposure on explants viability, recovery and cryobehaviour should be tested for each variety/cultivar before wider application of cryostorage. The Polytechnic of Agriculture and Cattle Husbandry at the University of Manabi (Ecuador) is conducting a project aiming at collecting, characterizing and conserving the genetic resources of wild tomato species (including rare and endangered accession) also in a form of a cryobank (Zhang et al. 2014). Such projects are necessary for plant biodiversity protection and sustainable management, and shortly will be carried out also in other institutions all over the world.

Author contributions DK analyzed the available literature, wrote and prepared the manuscript.

Funding No funding was received. 


\section{Compliance with ethical standards}

Conflict of interest The author declares that he has no conflict of interest.

Open Access This article is distributed under the terms of the Creative Commons Attribution 4.0 International License (http://creativecommons.org/licenses/by/4.0/), which permits unrestricted use, distribution, and reproduction in any medium, provided you give appropriate credit to the original author(s) and the source, provide a link to the Creative Commons license, and indicate if changes were made.

\section{References}

Abdul-Baki AA (1992) Determination of pollen viability in tomatoes. J Am Soc Hort Sci 117(3):473-476

Al-Abdallat AM, Shibli RA, Akash MW, Rabbaa M, Al-Qudah T (2017) In vitro preservation of transgenic tomato (Solanum lycopersicum L.) plants overexpressing the stress-related SlAREB1 transcription factor. Int J Mol Sci 18(7):1477. https://doi.org/10.3390/ijms18071477

Albrecht E, Escobar M, Chetelat RT (2010) Genetic diversity and population structure in the tomato-like nightshades Solanum lycopersicoides and S. sitiens. Ann Bot 105(4):535-554. https://doi.org/10.1093/ aob/mcq009

Alexander MP, Ganeshan S (1989) Preserving viability and fertility of tomato and eggplant pollen in liquid nitrogen. Indian J Plant Genet Res 2:140-144

Archak S, Karihaloo JL, Jain A (2002) RAPD markers reveal narrowing genetic base of Indian tomato cultivars. Curr Sci 82(9):1139-1142

Bauchet G, Causse M (2012) Genetic diversity in tomato (Solanum lycopersicum) and its wild relatives. In: Caliskan M (ed) Genetic Diversity in Plants. InTech, London, pp 133-162. https://doi. org/10.5772/33073

Belletti P, Lanteri S, Lepori G, Nassi MO, Quagliotti L (1990) Factors related to the cryopreservation of pepper and eggplant seeds. Adv Hortic Sci 4(2):118-120

Berry T, Bewley JD (1991) Seeds of tomato (Lycopersicon esculentum Mill) which develop in a fully hydrated environment in the fruit switch from a developmental to a germinative mode without a requirement for desiccation. Planta 186(1):27-34. https://doi.org/10.1007/bf00201494

Bhattarai K, Louws FJ, Williamson JD, Panthee DR (2016) Diversity analysis of tomato genotypes based on morphological traits with commercial breeding significance for fresh market production in eastern USA. Aust J Crop Sci 10(8):1098-1103. https://doi.org/10.21475/ajcs.2016.10.08.p7391

Boyle R (1665) New experiments and observations upon cold

Cebolla-Cornejo J, Roselló S, Nuez F (2013) Phenotypic and genetic diversity of Spanish tomato landraces. Sci Hortic 162:150-164. https://doi.org/10.1016/j.scienta.2013.07.044

Condello E, Caboni E, Andre E, Piette B, Druart R, Swennen R, Panis B (2011) Cryopreservation of apple in vitro axillary buds using droplet-vitrification. CryoLett 32(2):175-185

Coste A, Deliu C, Valimareanu S, Halmagyi A (2014) Cryopreservation and acclimatization of Lycopersicon esculentum (Mill.) genotypes. Not Bot Horti Agrobo 42(2):466-471. https://doi.org/10.15835/ nbha4229579

Coste A, Şuteu D, Bacila I, Deliu C, Valimareanu S, Halmagyi A (2015) Genetic integrity assessment of cryopreserved tomato (Lycopersicon esculentum Mill.) genotypes. Turk J Biol 39:638-648. https://doi. org/10.3906/biy-1411-6

Ebert AW (2012) Ex situ conservation of plant genetic resources of major vegetables. In: Normah MN et al (eds) Conservation of tropical plant species. Springer, Tainan, pp 373-417. https://doi. org/10.1007/978-1-4614-3776-5_16

Edesi J, Kotkas K, Pirttilä AM, Häggman H (2015) The effect of light spectral quality on cryopreservation success of potato (Solanum tuberosum L.) shoot tips. Cryobiology 71(3):566. https://doi.org/10.1016/j. cryobiol.2015.10.124

Edesi J, Pirttilä AM, Häggman H (2017) Modified light spectral conditions prior to cryopreservation alter growth characteristics and cryopreservation success of potato (Solanum tuberosum L) shoot tips in vitro. Plant Cell Tissue Organ Cult 128(2):409-421. https://doi.org/10.1007/s11240-016-1119-X

Engelmann F (2014) Cryopreservation of clonal crops: a review of key parameters. Acta Hortic 1039:3139. https://doi.org/10.17660/ActaHortic.2014.1039.2 
Fabre J, Dereuddre J (1990) Encapsulation-dehydration: a new approach to cryopreservation of Solanum shoot-tips. CryoLett 11:413-426

FAO (2014) Genebank standards for plant genetic resources for food and agriculture. FAO, Rome

Fentik DA (2017) Review on genetics and breeding of tomato (Lycopersicon esculentum Mill.). Adv Crop Sci Tech 5(5):306

Ganeshan S, Rajasekharan PE (2005) Preservation and management of haploid diversity through pollen cryopreservation. J. Palynol 41:39-48

Giovannoni J (2018) Tomato multiomics reveals consequences of crop domestication and improvement. Cell 172(1-2):6-8. https://doi.org/10.1016/j.cell.2017.12.036

Gonçalves LSA, Rodrigues R, Amaral Júnior AT, Karasawa M, Sudré CP (2008a) Comparison of multivariate statistical algorithms to cluster tomato heirloom accessions. Genet Molec Res 7(4):1289-1297

Gonçalves LSA, Rodrigues R, Sudré CP, Bento CS, Moulin MM, Araújo ML (2008b) Genetic divergence among tomato accessions using RAPD markers and its comparison with multicategoric descriptors. Hortic Bras 26(3):364-370. https://doi.org/10.1590/S0102-05362008000300014

Grout BWW (1980) Low temperature storage of imbibed tomato seeds: a model for recalcitrant seed storage. CryoLett 1(2):71-76

Grout BWW, Crisp PC (1995) Cryopreservation of germplasm of tomato. Biotechnol Agricult For 32:371380. https://doi.org/10.1007/978-3-662-03096-7_26

Grout BWW, Henshaw GG (1978) Freeze preservation of potato shoot-tip cultures. Ann Bot 42:1227-1229. https://doi.org/10.1093/oxfordjournals.aob.a085565

Grout BWW, Westcott RJ, Henshaw GG (1978) Survival of shoot meristems of tomato seedlings frozen in liquid nitrogen. Cryobiology 15(4):478-483. https://doi.org/10.1016/0011-2240(78)90068-8

Halmagyi A, Coste A, Tripon S, Crăciun C (2017) Low temperature induced ultrastructural alterations in tomato (Lycopersicon esculentum Mill.) shoot apex cells. Sci Hortic 222:22-31. https://doi. org/10.1016/j.scienta.2017.04.019

Hichri I, Muhovski Y, Žižková E, Dobrev PI, Gharbi E, Franco-Zorrilla JM et al (2017) The Solanum lycopersicum WRKY3 transcription factor SIWRKY3 is involved in salt stress tolerance in tomato. Front Plant Sci. https://doi.org/10.3389/fpls.2017.01343

Karapanos IC, Akoumianakis KA, Olympios CM, Passam HC (2010) Tomato pollen respiration in relation to in vitro germination and pollen tube growth under favourable and stress-inducing temperatures. Sex Plant Reprod 23(3):219-224. https://doi.org/10.1007/s00497-009-0132-1

Karipidis CH, Douma D (2011) Tomato pollen storage at freeze and cryogenic temperature-effects on viability and fecundity. Acta Hortic 908:257-263. https://doi.org/10.17660/ActaHortic.2011.908.33

Karipidis C, Lympios C, Passam HC, Savvas D (2007) Effect of moisture content of tomato pollen stored cryogenically on in vitro germination, fecundity and respiration during pollen tube growth. J Hortic Sci Biotechnol 82(1):29-34. https://doi.org/10.1080/14620316.2007.11512195

Keller ER, Dreiling M (2003) Potato cryopreservation in Germany-using the droplet method for the establishment of a new large collection. Acta Hortic 623:193-200. https://doi.org/10.17660/ActaHortic .2003 .623 .20

Keller ER, Kaczmarczyk A, Senula A (2008) Cryopreservation for plant genebanks-a matter between high expectations and cautious reservation. CryoLett 29:53-62

Kulus D (2018a) Genetic resources and selected conservation methods of tomato. J Appl Bot Food Qual 91:135-144. https://doi.org/10.5073/JABFQ.2018.091.00X

Kulus D (2018b) Molecular breeding of tomato-a mini review of recent discoveries. Sci Nat Technol. https ://doi.org/10.17306/J.NPT.00226

Kulus D, Zalewska M (2014) Cryopreservation as a tool used in long-term storage of ornamental species-a review. Sci Hortic 168:88-107. https://doi.org/10.1016/j.scienta.2014.01.014

Luyet BJ (1937) The vitrification of organic colloids and protoplasm. Biodinamica 29:1-15

Matilla AJ, Gallardo M, Puga-Hermida MI (2005) Structural, physiological and molecular aspects of heterogeneity in seeds: a review. Seed Sci Res 15(2):63-67. https://doi.org/10.1079/SSR2005203

Matsumoto T, Sakai A, Takahashi C, Yamada K (1995) Cryopreservation of in vitro-grown apical meristems of wasabi (Wasabia japonica) by encapsulation-vitrification method. CryoLett 16(4):189-196

Mazur P (1963) Kinetics of water loss from cells at subzero temperatures and the likelihood of intracellular freezing. J Gen Physiol 47(2):347-369

Miler N, Kulus D, Woźny A, Rymarz D, Hajzer M, Wierzbowski K, Nelke R, Szeffs L (2018) Application of wide-spectrum light-emitting diodes in micropropagation of popular ornamental plant species: a study on plant quality and cost reduction. In Vitro Cell Develop Biol Plant. https://doi.org/10.1007/ s11627-018-9939-5 
Montoya JE, Escobar Pérez RH, Debouck DG (2000) Development of a freezing methodology in liquid nitrogen of tree tomato (Cyphomandra betacea (Cav.) Sendt) seeds. Centro Internacional de Agricultura Tropical, Cali

Muntean CM, Leopold N, Tripon C, Coste A, Halmagyi A (2015) Surface-enhanced Raman spectroscopy of genomic DNA from in vitro grown tomato (Lycopersicon esculentum Mill.) cultivars before and after plant cryopreservation. Spectrochimica Acta A 144:107-114. https://doi.org/10.1016/j. saa.2015.02.085

Murashige T, Skoog F (1962) A revised medium for rapid growth and bio assays with tobacco tissue cultures. Physiol Plant 15:473-497. https://doi.org/10.1111/j.1399-3054.1962.tb08052.x

Nadarajan J, Pritchard HW (2014) Biophysical characteristics of successful oilseed embryo cryoprotection and cryopreservation using vacuum infiltration vitrification: an innovation in plant cell preservation. PLoS ONE 9(5):e96169. https://doi.org/10.1371/journal.pone.0096169

Niino T, Yamamoto SI, Fukui K, Castillo Martinez CR, Arizaga MV, Matsumoto T, Engelmann F (2013) Dehydration improves cryopreservation of mat rush (Juncus decipiens Nakai) basal stem buds on cryoplates. CryoLett 34(6):549-560

Nishizawa S, Sakai A, Amano Y, Matsuzawa T (1993) Cryopreservation of asparagus (Asparagus officinalis L.) embryogenic suspension cells and subsequent plant regeneration by vitrification. Plant Sci 91:6773. https://doi.org/10.1016/0168-9452(93)90189-7

Paupière MJ, van Haperen P, Rieu I, Visser RGF, Tikunov YM, Bovy AG (2017) Screening for pollen tolerance to high temperatures in tomato. Euphytica 213:130. https://doi.org/10.1007/s10681-017-1927-Z

Pegg DE (2002) The history and principles of cryopreservation. Semin Reprod Med 20(1):5-13

Polge C (1957) Low-temperature storage of mammalian spermatozoa. R Soc Lond 147:498-508. https://doi. org/10.1098/rspb.1957.0068

Pritchard H (1995) Cryopreservation of seeds. In: Day J, McLellan M (eds) Cryopreservation and freeze-drying protocols. Humana Press Inc., Totowa, NJ, pp 133-144. https://doi.org/10.1385/0-89603-296-5:133

Robertson LD, Labate JA (2006) Genetic resources of tomato (Lycopersicon esculentum Mill.) and wild relatives. In: Razdan MK, Mattoo AK (eds) Genetic improvement of Solanaceae crops, vol. 2: Tomato. Taylor and Francis, Boca Raton, pp 285-313. https://doi.org/10.1201/b10744-3

Rzepka-Plevneš D, Kulpa D, Palka E, Wisniewska M (2010) Somaclonal variability in callus culture of Lycopersicon hirsutum f. typicum and Lycopersicon chilense. Acta Sci Pol Hort Cult 4(9):63-73

Sacks EJ, St Clair DA (1996) Cryogenic storage of tomato pollen: effect on fecundity. HortScience 31(3):447-448

Sahu KK, Chattopadhyay D (2017) Genome-wide sequence variations between wild and cultivated tomato species revisited by whole genome sequence mapping. BMC Genomics 18:430. https://doi. org/10.1186/s12864-017-3822-3

Sakai A, Kobayashi S, Oiyama I (1990) Cryopreservation of nucellar cells of navel orange (Citrus sinensis Osb. var. brasiliensis Tanaka) by vitrification. Plant Cell Rep 9:30-33. https://doi.org/10.1007/BF002 32130

Sharifova S, Mehdiyeva S, Theodorikas K, Roubos K (2013) Assessment of genetic diversity in cultivated tomato (Solanum lycopersicum L) genotypes using RAPD primers. J Hortic Res 21(1):83-89. https:// doi.org/10.2478/johr-2013-0012

Shuren Z, Liying W, Minchang Y, Aihua C (1993) The cryopreservation of tomato pollen. Acta Hortic Sin 20:66-70

Song J, Tachibana S (2007) Loss of viability of tomato pollen during long-term dry storage is associated with reduced capacity for translating polyamine biosynthetic enzyme genes after rehydration. J Exp Bot 58(15-16):4235-4244. https://doi.org/10.1093/jxb/erm280

Tamta S, Singh JP (2017) Heterosis in tomato for growth and yield traits. Int J Veg Res 24(2):169-179. https ://doi.org/10.1080/19315260.2017.1407857

Tilden WA (2009) A short history of the progress of scientific chemistry in our own times. LLC, BiblioBazaar, p 249

Towill L (1985) Low temperature and freeze/vacuum-drying preservation of pollen. In: Kartha KK (ed) Cryopreservation of plant cells and organs. CRC Press, Boca Raton, pp 172-198

Van Eck J (2018) Genome editing and plant transformation of solanaceous food crops. Curr Opin Biotechnol 49:35-41. https://doi.org/10.1016/j.copbio.2017.07.012

Walters C (2004) Temperature dependency of molecular mobility in preserved seeds. Biophys J 86:12531258. https://doi.org/10.1016/S0006-3495(04)74199-5

Walters C, Wheeler L, Standwood P (2004) Longevity of cryogenically stored seeds. Cryobiology 48:229244. https://doi.org/10.1016/j.cryobiol.2004.01.007

Yamamoto S, Rafique T, Priyantha WS, Fukui K, Matsumoto T, Niino T (2011) Development of a cryopreservation procedure using aluminium cryo-plates. CryoLett 32(3):256-265 
Yi SS, Jatoi SA, Fujimura T, Yamanaka S, Watanabe J, Watanabe KK (2008) Potential loss of unique genetic diversity in tomato landraces by genetic colonization of modern cultivars at non-center of origin. Plant Breed 127(2):189. https://doi.org/10.1111/j.1439-0523.2007.01446.x

Zarghami R, Pirseyedi M, Hasrak S, Sardrood PB (2008) Evaluation of genetic stability in cryopreserved Solanum tuberosum. Afr J Biotechnol 7(16):2798-2802

Zevallos B, Cejas I, Rodríguez RC, Yabor L, Aragón C, González J et al (2013a) Biochemical characterization of Ecuadorian wild Solanum lycopersicum Mill plants produced from non-cryopreserved and cryopreserved seeds. CryoLett 37(4):413-421

Zevallos B, Cejas I, Valle B, Yabor L, Aragón C, González J et al (2013b) Short-term liquid nitrogen storage of wild tomato (Solanum lycopersicum Mill.) seeds modifies the levels of phenolics in 7 day-old seedlings. Sci Hortic 160:264-267. https://doi.org/10.1016/j.scienta.2013.06.002

Zevallos B, Cejas I, Engelmann F, Carputo D, Aversano R, Scarano M-T et al (2014) Phenotypic and molecular characterization of plants regenerated from non-cryopreserved and cryopreserved wild Solanum lycopersicum Mill. seeds. CryoLett 35(3):216-225

Zhang J, Xin X, Yin G, Lu X, Chen X (2014) In vitro preservation and cryopreservation in national genebank of China. Acta Hortic 1039:309-317. https://doi.org/10.17660/ActaHortic.2014.1039.39

Publisher's Note Springer Nature remains neutral with regard to jurisdictional claims in published maps and institutional affiliations. 